\title{
Compreendendo as diferenças de gênero a partir de interações livres no contexto escolar
}

\author{
Aline Beckmann de Castro Menezes \\ Universidade Federal do Pará \\ Regina Célia Souza Brito \\ Universidade de São Paulo \\ Renata Almeida Figueira \\ Tatiana Frazão Bentes \\ Eline Freire Monteiro \\ Marina Cunha Santos \\ Universidade Federal do Pará
}

\begin{abstract}
Resumo
Para a Psicologia Evolucionista as diferenças de gênero existentes nas brincadeiras resultam de influências culturais que interagem com uma pré-disposição selecionada na espécie. Objetivou-se investigar se tais diferenças seriam compatíveis com dimorfismo sexual descrito na literatura da área. Setenta e três alunos entre seis e sete anos de uma escola particular foram filmados em quatro sessões de 30 minutos de recreio. Contabilizou-se a freqüência dos comportamentos e os pares com que ocorriam. Posteriormente, 21 crianças foram entrevistadas sobre suas brincadeiras prediletas e suas classificações de brincadeiras segundo o gênero. Pôde-se observar que ambos os sexos participam de atividades similares, mas em interações intrasexuais. Além disso, observaram-se diferenças topográficas na forma de brincar, de acordo com o sexo. Nas entrevistas, como previa a literatura, foram registradas diferenças entre o relatado e o observado, indicando maior influência cultural sobre o conteúdo relatado.
\end{abstract}

Palavras-chave: brincadeira; gênero; psicologia evolucionista.

\begin{abstract}
Understanding gender differences through free interactions at scholar environment. Evolutionary Psychology considers that gender differences in play are a result of cultural influences upon pre-dispositions selected in the species. The compatibility of these differences with theoretical prevision was investigated. Seventy three six/seven years old students of private schools were recorded in four 30 minutes sessions. Playful behavior frequency and playmate choice were counted. Later, 21 children were asked about favourite plays and how they classified those plays accordingly to gender patterns. Both sexes participated in similar activities but their interactions were mostly restricted to members of the same sex. It was also observed that there were topographic differences in the way they played, accordingly to sex. The interviews, as shown in the literature, allowed to identify that the speech and the behavior observed were different, with a higher cultural influence upon the speech.
\end{abstract}

Keywords: play; gender; evolutionary psychology.

A s diferenças existentes entre os sexos podem ser observadas em características anatômicas, na fisiologia e no comportamento de diversas espécies. Na humana, a origem do dimorfismo sexual comportamental tem sido alvo de polêmicas reiteradas (Buss, 1995; Luxen, 2007).

Segundo Hansen et al. (2007), o dimorfismo sexual já foi observado em crianças a partir de um dia de vida, medido por meio da atenção (meninos direcionados mais a objetos e meninas a rostos humanos). Apesar da diversidade de padrões sexualmente dimórficos já estudados ser grande, o contexto da brincadeira tem sido privilegiado quando o foco é a infância (Burghardt, 2004). Isto porque, no contexto de brincadeira sem a interferência de adultos, as crianças constroem sua própria cultura, estabelecendo regras, valores, hierarquias e, conseqüentemente, construindo suas próprias identidades a partir da interação com os pares (Conti \& Sperb, 2001).

Silva (2006) relata que as diferenças entre os sexos se consolidam por volta dos cinco aos seis anos de idade. Tais 
diferenças são percebidas na preferência por brincadeiras, nos estilos de brincar, de interagir e de se comportar em sentido mais amplo.

Silveira (2003) entrevistou crianças de diferentes faixas etárias e encontrou que, principalmente entre cinco e oito anos de idade, a classificação de brincadeiras enquanto masculinas ou femininas tendeu a ser bastante rígida - superior, inclusive, a estudos, envolvendo a observação do brincar infantil.

Discutindo estas diferenças, Silva, Pontes, Silva, Magalhães e Bichara (2006) propõem o conceito de brincadeira predominantemente masculinas e predominantemente femininas, já que a presença de crianças de ambos os sexos é freqüente na maioria das brincadeiras, havendo, contudo, diferentes papéis e condutas assumidos por meninos e meninas nestas situações.

As diferenças existentes nos padrões típicos de gênero podem decorrer da segregação existente no brincar ou, inversamente, a segregação pode decorrer das diferenças de gênero (Silva, 2006).

Vários estudos discutem as diversas formas de brincar observadas em cada espécie. Contudo, a função do brincar para tais indivíduos ainda não é consensual. Hansen et al. (2007) apresentam as duas perspectivas mais comuns, uma focando em benefícios para a vida adulta (como o treino de habilidades) e outra defendendo benefícios imediatos (como a interação social e o próprio prazer obtido com o brincar). A perspectiva mais moderna, que tem sido defendida por muitos autores, inclusive Hansen et al. (2007), refere-se à combinação de ambas as perspectivas.

Burghardt (2004), ilustrativamente, afirma que nem toda forma de brincar tem a mesma origem neurobiológica ou evolutiva. Ao longo da evolução, o brincar adquiriu diversas funções, favorecendo a complexidade comportamental, emocional e cognitiva. Este autor discute, ainda, que o brincar teria funções imediatas, em especial na infância, e preparatórias (favorecendo o desenvolvimento de habilidades e características necessárias para a vida adulta). As funções imediatas estariam relacionadas, por exemplo, ao desenvolvimento perceptual e motor e de habilidades de comunicação que fossem fundamentais para a sobrevivência ao estágio do desenvolvimento em questão. Pode-se considerar, desta forma, que tanto por suas funções imediatas quanto pelas preparatórias, o brincar seria resultado da história evolutiva. $\mathrm{O}$ autor destaca, ainda, que na espécie humana a influência da cultura e da sociedade não pode ser ignorada, mas afirma que as diferenças existentes entre machos e fêmeas (como forrageio, socialização, reprodução, esquiva de predadores, etc.) possuem predisposições genéticas, hormonais e neurais, de modo que há de se esperar tais diferenças também no brincar.

A base sobre a qual estas predisposições se assentam é descrita por Biddulph (2006). Segundo este autor, em crianças do sexo masculino, aos quatro anos de idade, os níveis de testosterona dobram, refletindo-se em comportamentos mais agitados e brincadeiras movimentadas. Aos cinco anos, a testosterona cai pela metade e a criança tende a se acalmar um pouco, mas mantém as preferências por atividades mais turbulentas. Quanto ao desenvolvimento cerebral, crianças do sexo masculino têm seus cérebros desenvolvidos mais lentamente e com menos conexões entre os hemisférios esquerdo e direito, devido à reduzida ação do estrogênio. $\mathrm{Na}$ faixa dos seis aos sete anos, o desenvolvimento mental, especialmente da coordenação motora fina, das crianças do sexo masculino é de seis a 12 meses atrasado relativamente às do sexo feminino (Biddulph, 2006). É nesta faixa etária também que, segundo Ellis (2004), ocorre a adrenarca, isto é, o despertar das glândulas adrenais implicando mudanças físicas e no desenvolvimento das respostas biocomportamentais sexualmente dimórficas frente ao estresse, com homens adotando o padrão de luta-ou-fuga e mulheres de proteção-e-aproximação (Taylor et al., 2000). Estas características fisiológicas díspares para meninos e meninas podem indicar a importância delas para a sobrevivência das crianças no ambiente de seleção da espécie humana.

Ainda buscando as bases do dimorfismo, Van de Beek, van Goozen, Buitelaar e Cohen-Kettenis (2009) afirmam que a preferência por brinquedos, sendo bonecas e utensílios domésticos escolhidos pelo sexo feminino, e veículos e armas pelo masculino, é um dos padrões de comportamentos no qual se pode observar o dimorfismo mais precocemente. Segundo estes autores, o dimorfismo sexual no comportamento humano seria decorrente de alterações no desenvolvimento cerebral fetal a partir da influência de hormônios pré-natais (especialmente durante o pico de testosterona, entre as semanas 8 e 12 da gravidez). Estes autores encontraram índices significativamente superiores de testosterona no líquido amniótico de fetos do sexo masculino e de estradiol nos fetos do sexo feminino. As crianças deste estudo foram observadas novamente aos 13 meses de idade, demonstrando preferência por brinquedos masculinos por parte dos meninos e por brinquedos femininos pelas meninas. Os autores discutem este dado como evidência da relação entre produção hormonal intra-uterina e preferências infantis.

Não se propõe, todavia, que a cultura seja descartada a partir de evidências da relação entre produção hormonal e dimorfismo sexual (bem como outras evidências existentes na literatura da área, que indicam influências biológicas sobre o comportamento). A cultura e a ontogênese podem "diminuir, exagerar ou ainda inverter as diferenças sexuais", já que "masculinidade-feminilidade é uma das dimensões culturais fundamentais" (Luxen, 2007, p. 383). Contudo, a Psicologia Evolucionista propõe que os diferentes papéis assumidos ao longo da história evolutiva geraram diferentes pressões seletivas e, conseqüentemente, o desenvolvimento de mecanismos cognitivos especializados para cada sexo (Buss, 1995). Desta forma, "papéis sexuais fazem sentido sob o ponto de vista evolucionista" (Luxen, 2007, p. 391) e as hipóteses evolucionárias sobre as diferenças sexuais demonstram ter poder heurístico e preditivo (Buss, 1995).

O presente trabalho propõe a investigação das diferenças sexuais no comportamento de crianças de aproximadamente sete anos, em contexto de brincadeira livre. Como já apontado pela literatura, espera-se encontrar a distribuição dos comportamentos enquanto predominantemente masculinos, predominantemente femininos ou gerais (Silva et al., 2006). A pergunta aqui proposta é se estas diferenças observadas no contexto do brincar seriam compatíveis com o dimorfismo sexual previsto a partir da 
perspectiva evolucionista. Para tal, propõe-se a observação das diferenças sexuais presentes no brincar livre e a discussão destas diferenças sob o olhar da Psicologia Evolucionista.

Além disso, pretende-se investigar se as normas sócioculturais, por sua vez, iriam ao encontro desta tendência evolutivamente selecionada, fortalecendo ou enfraquecendo noções de masculino e feminino. Carvalho, Beraldo, Pedrosa e Coelho (2004) discutem o uso de entrevistas com crianças e afirmam que "seus relatos tentam aproximar suas respostas daquelas que se supõem mais aceitas socialmente" (p. 293). Desta forma, propõe-se que a amplitude da influência social poderá ser investigada através da comparação da segregação sexual explicitada no discurso infantil e daquela observada diretamente no comportamento.

\section{Método}

\section{Participantes}

Participaram da Fase 1 desta pesquisa 73 alunos (sendo 41 do sexo masculino e 32 do sexo feminino) pertencentes a duas classes da primeira e duas classes da segunda série do ensino fundamental, com idades entre 6 e 7 anos, regularmente matriculados em uma escola particular da cidade de Belém, Pará. Na Fase 2, participaram 21 alunos (sendo 12 do sexo masculino e 11 do feminino) do mesmo grupo original.

Foram admitidos como participantes apenas aqueles alunos cujos pais ou responsáveis autorizaram oficialmente a realização da pesquisa, através da assinatura do Termo de Consentimento Livre e Esclarecido ${ }^{1}$.

\section{Ambiente}

A pesquisa foi conduzida no ambiente escolar. A escola escolhida possui um projeto pedagógico inclusivo de crianças portadoras de necessidades especiais e de aceitação de padrões comportamentais típicos do sexo oposto (como meninas jogando futebol).

As observações ocorreram no recreio, em um espaço de aproximadamente $1.442 \mathrm{~m}^{2}$, com revestimento predominantemente de areia (partes em grama e passarelas em concreto $^{2}$ ). Havia dois acessos à área, ambos localizados nas laterais dos refeitórios existentes. As crianças circulavam por todo o espaço, concentrando-se na área livre e no parquinho (composto por oca; casinha - simulando uma casa; casa do parque - com escorrega, gangorra, argola, rampa etc.; Gira-Gira; balanço; gangorra; escorrega).

\section{Material e equipamento}

Foram utilizados: caneta; folha de registro de observação; questionários de classificação de brincadeiras - adaptados de Beraldo (1993); cinco câmeras de vídeo; 16 fitas de vídeo e quatro mini-dvds.

A folha de registro continha quatro colunas, em uma das quais havia as categorias comportamentais, já preenchidas; nas demais eram feitos registros de acordo com os pares com quem ocorria a categoria (só; apenas com meninos; apenas com meninas; ou misto). O questionário foi adaptado para utilização de brincadeiras que fizessem parte do contexto real das crianças, sendo as mesmas escolhidas a partir das sessões de observação.

\section{Procedimento}

Fase 1 - Observação e registro. Inicialmente foram realizadas três sessões, de aproximadamente $30^{\prime}$ cada, de registro cursivo simultaneamente a partir de cinco diferentes pontos, objetivando: familiarizar as pesquisadoras com o ambiente; reduzir o impacto de suas presenças frente ao comportamento das crianças e possibilitar a elaboração de categorias comportamentais. Após as sessões iniciais, foram filmadas quatro sessões de aproximadamente 30' cada, uma por semana, sempre durante o recreio.

Foi contabilizado, a cada minuto, o número de ocorrências de cada categoria comportamental apenas por pessoas do sexo feminino, registrando o grupo com o qual interagia. Não foi registrada a duração da ocorrência. Repetiu-se, então, o procedimento para os participantes do sexo masculino. Para considerar a criança como parte de um grupo, observava-se tanto a proximidade física quanto o engajamento na mesma atividade que as demais. As quatro sessões de registro filmado totalizaram 4h:28m:45s de filmagem em condições de análise, considerando os cinco pontos de observação.

Fase 2-Entrevistas. Na Fase 2, foram realizadas entrevistas individuais com os 21 participantes cujos pais ou responsáveis autorizaram a participação, utilizando o questionário de classificação de brincadeiras, adaptado de Beraldo (1993). O questionário era dividido em duas partes.

A primeira parte do instrumento constava de quatro perguntas: 1. Qual sua brincadeira predileta? 2. Por quê? 3. Onde você costuma brincar disso? 4. Com quem você costuma brincar disso? Todas as questões eram repetidas para as quatro brincadeiras prediletas do participante. No registro da quarta resposta ("com quem...") era anotado o sexo das pessoas com quem compartilhavam a brincadeira.

A segunda parte constava da lista de nove comportamentos selecionados a partir dos resultados da Fase 1, sendo três mais freqüentes entre meninos (correr, brincar de luta, brincar na oca), três mais freqüentes entre meninas (conversar, gangorrear e dançar) e três mais freqüentes para ambos (brincar no Gira-Gira, cavar a areia e brincar de pega-pega). Era lido um comportamento e feitas três perguntas ao participante: 1. Quem faz mais isso é menino, menina ou os dois? 2. Por quê? 3. Você faz isso?

Estando o pesquisador e a criança na brinquedoteca, era feita uma interação informal com o participante explicando que seriam feitas perguntas sobre brincadeiras e que ele podia solicitar a interrupção da entrevista a qualquer momento.

\section{Resultados e Discussão}

Na Fase 1, as três sessões de registro cursivo possibilitaram a criação de categorias comportamentais para análise e a familiarização com o ambiente e os participantes. A interferência externa foi minimizada ao longo das sessões.

Foram registradas 65 categorias comportamentais diferentes, sendo analisadas apenas aquelas com freqüência superior a 10 ocorrências para qualquer sexo, totalizando 
21 categorias $^{3}$. Foi calculado, então, para cada categoria, se esta se ocorria predominantemente em participantes do sexo feminino (compondo a macro-categoria "Feminino"), do sexo masculino (compondo a macro-categoria "Masculino") ou se não predominava em nenhum dos casos (compondo a macro- categoria "Geral"). Para ser incluída em cada categoria, era necessário que mais de $70 \%$ das ocorrências fossem registradas naquele grupo específico.

A Tabela 1 apresenta as Macro-categorias, com seus respectivos percentuais de ocorrência: 90\% (Feminino), 80\%

Tabela 1

Macro-categorias definidas a partir da observação

\begin{tabular}{|c|c|c|c|}
\hline \multirow{2}{*}{ Macro- Categoria } & \multirow{2}{*}{ Comportamentos } & \multicolumn{2}{|c|}{ \% Concordância } \\
\hline & & Item & Categoria \\
\hline \multirow{7}{*}{ Feminino } & Gangorrear & $100 \%$ & \multirow{7}{*}{$90 \%$} \\
\hline & Sentar um atrás do outro & $100 \%$ & \\
\hline & Sentar no alto do Gira-gira & $98 \%$ & \\
\hline & Balançar no banco das professoras & $95 \%$ & \\
\hline & Falar com o observador & $93 \%$ & \\
\hline & Ser girado estando sentado & $71 \%$ & \\
\hline & Sentar no banco das professoras & $70 \%$ & \\
\hline \multirow{2}{*}{ Masculino } & Brincar com o observador & $82 \%$ & \multirow{2}{*}{$80 \%$} \\
\hline & Brincar de luta & $78 \%$ & \\
\hline \multirow{12}{*}{ Geral } & Girar por fora do Gira-gira & $96 \%$ & \multirow{12}{*}{$81 \%$} \\
\hline & Falar/Conversar & $95 \%$ & \\
\hline & Andar & $87 \%$ & \\
\hline & Cavar a areia & $86 \%$ & \\
\hline & Dar as mãos & $86 \%$ & \\
\hline & Girar sentando & $84 \%$ & \\
\hline & Pendurar-se no Gira-gira & $77 \%$ & \\
\hline & Sentar & $76 \%$ & \\
\hline & Observar grupo & $74 \%$ & \\
\hline & Observar um colega & $73 \%$ & \\
\hline & Correr & $70 \%$ & \\
\hline & Girar por dentro do Gira-gira & $68 \%$ & \\
\hline
\end{tabular}

(Masculino) e 81\% (Geral).

$\mathrm{Na}$ macro-categoria "Feminino", foram inseridas sete categorias. Destas, três estão relacionadas diretamente à interação social: "gangorrear" (requer um segundo participante); "sentar um atrás do outro" (brincadeira de trenzinho, requerendo a participação de outras pessoas); "falar com o observador" (interação verbal); "ser girado estando sentado" (interação passiva, já que requer a ação de outra pessoa para o brinquedo funcionar). Duas indicam a busca por interação e/ou contato: "sentar no banco das professoras" e "balançar no banco das professoras". É importante ressaltar que a escolha daquele banco em particular estava relacionada à presença das professoras, já que na ausência delas, outros bancos e balanços eram escolhidos.

Buss (1995) afirma que as mulheres tendem a possuir mais habilidades verbais que homens. Contudo, o presente dado não reflete apenas as habilidades existentes. Pode-se considerar que a busca por atividades que envolvam a coordenação de ações com um parceiro, e que sejam interativas, era funcional no ambiente de adaptação evolutiva, já que as mulheres tendiam a criar as crianças e realizar atividades domésticas em conjunto. Supõemse, assim, funções imediatas e posteriores à busca pela interação, já que a proximidade a outras meninas e a mulheres mais velhas favoreceria a aprendizagem de habilidades necessárias à sua sobrevivência, bem como a proteção frente a perigos iminentes.
A categoria "sentar no alto do Gira-Gira", também inserida na macro-categoria "Feminino", implica habilidade motora e de equilíbrio refinados. Biddulph (2006) dá indícios de que com o desenvolvimento motor mais precoce, as participantes do sexo feminino teriam, nesta idade, maiores condições de desempenhar comportamentos que demandem habilidades como equilíbrio.

Na macro-categoria "Masculino", foram inseridas apenas duas categorias: "brincar com o observador" e "brincar de luta". Este resultado reflete dois aspectos do dimorfismo sexual no contexto de brincadeira. $\mathrm{O}$ primeiro é a maior freqüência de brincadeiras turbulentas entre os meninos (Cordazzo, Westphal, Tagliari, Vieira, \& Oliveira, 2008). Nestas se enquadram ambas as categorias aqui inseridas, já que as brincadeiras com o observador ocorriam principalmente quando os participantes do sexo masculino estavam correndo e interagiam a partir de brincadeiras agitadas (como pulos, gritos, caretas, etc.), como foi observado em $87 \%$ das interações. Já as meninas tendiam a passar próximo das câmeras andando e, assim, quando buscavam interação, tendiam a fazê-lo a partir do diálogo ( $90 \%$ das vezes em que interagiram com o observador).

Outro aspecto é o número reduzido de categorias. É importante ressaltar ainda que, como já foi observado anteriormente na literatura (Hansen et al., 2007; Silva, 2006), a aceitação de meninas em grupos masculinos é superior ao 
inverso. Em decorrência disto, observa-se um maior número de categorias femininas do que masculinas, pois algumas brincadeiras preferidas pelos meninos não foram enquadradas na macro-categoria "Masculino" em função da elevada inserção feminina nas mesmas.

Por exemplo, apesar de "correr" ser inserida na macrocategoria "Geral" (por ter $70 \%$ de chance de ocorrer tanto com um sexo quanto com outro), em $75 \%$ dos registros havia indivíduos do sexo masculino envolvidos no comportamento. Isto se deve ao fato que este era um comportamento freqüente entre meninos de um modo geral, enquanto que tendia a ser mais freqüente entre as meninas na presença de indivíduos do sexo masculino.

Taylor et al. (2000), discutem a inserção de mulheres em grupos masculinos sob outra perspectiva complementar. Segundo esses autores, a busca por fêmeas em se inserir em grupos masculinos teria muitas vantagens adaptativas, pois aumentaria a sua proteção por machos e, paralelamente, diminuiria a probabilidade de vitimização pelos mesmos. Essa demanda de proteção teria exercido uma pressão seletiva, de modo que a atração feminina por pertencer a grupos masculinos teria sido selecionada, tornando-se um mecanismo cognitivo inconsciente e, logo, podendo se manifestar em diferentes faixas etárias e contextos.

Na macro-categoria "Geral", foram inseridas 12 categorias. Este elevado número de categorias demonstra que a maioria das atividades é desempenhada por participantes de ambos os sexos. Deste modo, pode-se hipotetizar que a adoção de muitos padrões de interação e tipos de brincadeiras é potencialmente similar entre os sexos, mas práticas culturais de segregação intensificam diferenças existentes, como as de cunho biológico já discutidas. Estes dados corroboram a proposta de Silva et al. (2006) da terminologia "predominantemente feminino" e "predominantemente masculino", indicando que a exclusividade de gênero em uma brincadeira é menos freqüente.

Contudo, a análise das ocorrências dentro da macrocategoria "Geral" indica que há diferenças sexuais mesmo em brincadeiras comuns a ambos os sexos. Por exemplo, as categorias "falar/conversar" e "dar as mãos" tiveram 95\% e $86 \%$ de probabilidade, respectivamente, de ocorrer para ambos os sexos. Contudo, apenas $48 \%$ e $43 \%$ das ocorrências foram no sexo masculino. Pôde-se perceber, ainda, que $79 \%$ das ocorrências foram exclusivamente intra-sexuais, indicando que, apesar de ocorrerem em ambos os sexos, estas categorias podem possuir diferentes funções.

A literatura tem sugerido que indivíduos do sexo masculino precisavam ter desenvolvido habilidades relativas à formação de redes sociais que possibilitassem a manutenção/aquisição de status e poder político, além de estarem primordialmente vinculados a partir de uma tarefa específica em desenvolvimento. Por outro lado, a vinculação entre indivíduos do sexo feminino teria o objetivo de criar redes sociais de apoio mútuo e afetividade, favorecendo o auxílio em determinadas tarefas relativas ao cuidado parental e à construção de laços socioemocionais. Desta forma, a vinculação estabelecida entre indivíduos do sexo masculino pode ser considerada tão importante quanto entre indivíduos do sexo feminino, mas ainda assim diferente (Taylor et al., 2000).

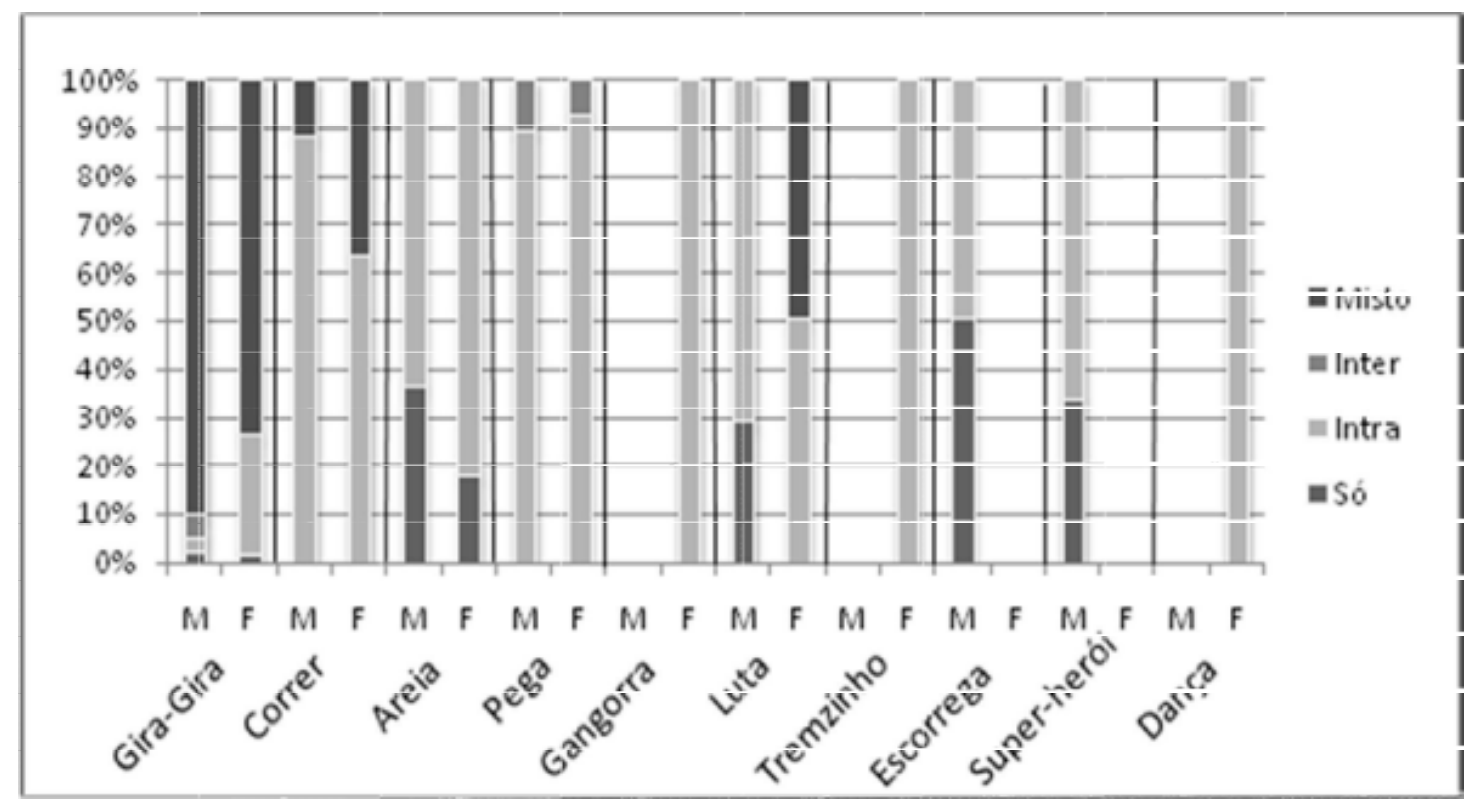

Figura 1. Proporção das formas de ocorrência de brincadeiras de acordo com o sexo do participante

Legenda: só refere-se a registros de ocorrências em que o participante brincava sozinho; a legenda intra, referese a quando todos os participantes da brincadeira eram do mesmo sexo; a legenda inter refere-se a quando a criança alvo da observação é a única do seu sexo em um grupo de participantes do sexo oposto; por fim, a legenda misto refere-se a grupos com pelo menos dois representantes de cada sexo interagindo juntos. 
Com o objetivo de aprofundar a análise das brincadeiras, agruparam-se as diferentes formas de brincar em 10 categorias, as quais se encontram na Figura 1.

A brincadeira mais freqüente foi "girar no Gira-Gira", com 687 registros (39\% por meninos e 61\% por meninas), demonstrando-se como mista, havendo indivíduos de ambos os sexos presentes em $80 \%$ dos registros. Vale ressaltar que a presença de um grupo de meninas no brinquedo não impedia a presença de um único menino, enquanto que o inverso não ocorria, possivelmente porque raramente o Gira-Gira foi observado sem a presença de meninas ( $2 \%$ das situações), de modo que estar nesse brinquedo implicava quase obrigatoriamente brincar com as meninas. Essa interpretação foi corroborada posteriormente a partir da entrevista com um menino que relatou que o Gira-Gira era um brinquedo de ambos os sexos "porque os meninos não podem expulsar as meninas de lá” (sic).

As brincadeiras "brincadeira de areia" e "jogos de pega" foram freqüentes para ambos os grupos, contudo, foram registradas em $96 \%$ das ocorrências em interações intrasexuais. Algumas brincadeiras foram registradas apenas por participantes do sexo masculino ("escorregar" e "brincar com bonecos de super-herói”) e outras apenas por participantes do sexo feminino ("gangorrear, sentar em trenzinho" e "dançar").

Apesar de esses dados contribuírem para o estudo das diferenças de gênero no brincar, buscou-se compreender a segregação sexual em brincadeiras comuns a ambos os sexos. Del Giudice (2009) afirma que em alguns casos as diferenças entre os sexos são qualitativas e não quantitativas, de modo que a forma com que os dados são tratados pode indicar erroneamente uma similaridade comportamental que, sob uma análise mais detalhada, seria reduzida. Assim, buscou-se observar diferenças topográficas em uma mesma brincadeira.

Este foi o caso das formas de brincar no Gira-Gira. Além de a freqüência ter sido superior para o sexo feminino, houve duas topografias exclusivas do grupo feminino ("ser girado estando deitado" e "ficar em pé no Gira-Gira") e duas outras topografias com predominância de $98 \%$ e $71 \%$ neste sexo ("sentar no alto" e "ser girado estando sentado", respectivamente).

"Brincar de areia" ocorreu $60 \%$ das vezes no grupo feminino e $40 \%$ das vezes no masculino. Contudo, percebeu-se que apenas no sexo masculino ocorreram brincadeiras como "chutar a areia" e "pegar areia e jogar nos outros", ainda que cada uma representasse apenas 3\% das ocorrências. Por outro lado, apenas no grupo feminino foi observada a brincadeira "fazer bolinho" (com 18\% das ocorrências totais). Apesar de aparentemente "cavar a areia" ter sido a forma de interação mais freqüente tanto no grupo masculino quanto no feminino (com $32 \%$ e $42 \%$ das ocorrências totais, respectivamente), ainda assim este padrão ocorria apenas intragrupo. Pôde-se perceber que as meninas tendiam a passar mais tempo nesta atividade, fazendo buracos rasos e espalhando a areia (enfeites) enquanto os meninos faziam buracos mais fundos, "muralhas" e mudavam de brincadeira mais rapidamente. Este resultado indica a riqueza de uma brincadeira particular, especialmente para estudos de gênero. Sugere-se, assim, estudos posteriores focados em diferentes derivações de uma brincadeira mais ampla.

Os “jogos de pega" também foram freqüentes em ambos os grupos, mas predominantes em interações intra-sexuais $(91 \%$ dos registros). A forma de brincar mais freqüente de cada grupo ("pira-bola" no masculino e "polícia e ladrão" no feminino) não foi registrada como ocorrendo entre os participantes do outro grupo. Essa diferença corrobora expectativas da literatura de que meninos tenderiam a variações mais turbulentas e as meninas privilegiariam jogos em equipes e com regras mais definidas (Burghardt, 2004). Além disso, o "pega-pega", que foi registrado com freqüência similar em ambos os grupos, ocorreu apenas em interações intra-sexuais.

Essa distribuição sexual nas variações dos "jogos de pega" reflete, além das diferenças nas preferências pelo estilo de brincadeira, a predileção por pares do mesmo sexo. Este dado corrobora os achados com a aplicação da Entrevista Estruturada de Preferências de Parcerias e Estilos de Brincadeiras, desenvolvido por Alexander e Hines (1994). Estes autores encontraram uma forte correlação entre o sexo do participante e o sexo do parceiro escolhido, bem como entre o sexo do participante e os estímulos escolhidos (classificados como estímulos masculinos ou femininos). Em condições em que havia conflito entre a brincadeira e o gênero do parceiro (meninos com brincadeiras tipicamente femininas e vice-versa), foi encontrada uma predominância por escolhas baseadas no estímulo, em detrimento da parceria. Assim, pode-se perceber um padrão similar a este quando as crianças escolhiam prioritariamente brincadeiras típicas do seu sexo e, quando se engajavam na mesma brincadeira, escolhiam parceiros do mesmo sexo.

Na Fase 2, foram analisadas as 21 entrevistas, sendo $11 \mathrm{com}$ participantes do sexo feminino e 10 com o sexo masculino. $\mathrm{Na}$ pergunta sobre as brincadeiras prediletas, foram classificadas como "outros" todas as brincadeiras que foram mencionadas por apenas um participante. Das 25 brincadeiras inseridas nesta legenda, apenas duas apareceram tanto para o sexo feminino quanto para o masculino ("cartas" e "quebra-cabeça"). Quanto à variabilidade, o sexo masculino apresentou um maior número de brincadeiras, sendo $50 \%$ das respostas diferentes entre si (ver televisão; ben-dez (relógio); memória; luta; jacaré; iô-iô; garrafão; galo; cobra grande; casinha; bicicleta; balanço; ação (monstro, fantasma $)^{6}$ ). O sexo feminino obteve $39 \%$ de respostas diferentes (pular; patins; pata cega; nadar; elástico; dentro e fora; correr e comidinha). Pode-se perceber perfis diferentes de preferências, sendo as brincadeiras destacadas pelos meninos mais turbulentas que as das meninas.

As brincadeiras "pega" e "desenho" foram as únicas mencionadas por ambos os sexos. Pode-se destacar, contudo, a presença das brincadeiras "boneco" (com quatro registros no sexo masculino) e "boneca" (com três registros no sexo feminino), nas quais o gênero do brinquedo era atribuído espontaneamente pelas crianças, com exemplos de brinquedos muito diferentes por meninos e meninas (como heróis/monstros e bebês, respectivamente).

Outra diferença que pode ser destacada refere-se às formas de brincar de "pega". As participantes do sexo feminino apresentaram oito diferentes variações da brincadeira, enquanto que os do sexo masculino apresentaram cinco - o que corrobora os dados obtidos na Fase 1 (Hansen et al., 2007; Silva, 2006).

Quando questionados quanto ao porquê de preferirem tais 
brincadeiras, os participantes demonstraram dificuldade em explicar. Aproximadamente metade das respostas foi descritiva da ação, seguida da resposta "porque gostam" (30\% das situações) e "porque é fácil" ou "porque ganham" (10\% das vezes). No sexo masculino observou-se ainda a resposta "porque é coisa de menino" enquanto que no sexo feminino apareceram respostas de competição e estética (referentes a orientações maternais sobre emagrecimento).

Os locais citados pelos participantes como aqueles onde ocorrem as brincadeiras favoritas foram: casa, escola, rua, casa da avó, fazenda/sítio, caratê e praia. De forma compatível com a amostra - crianças urbanas de classe média - percebeu-se a predominância da casa e da escola. Quando perguntados com quem costumam brincar das brincadeiras citadas como preferidas, os participantes tenderam a citar pares da mesma faixa etária ( $95 \%$ das respostas) e do mesmo sexo (78\% das respostas femininas e 55\% das masculinas). Foi mais comum que participantes do sexo masculino citassem pares do sexo oposto do que o contrário, o que corrobora os dados de maior inserção do sexo feminino no universo lúdico masculino (Hansen et al., 2007).

A segunda etapa da entrevista consistiu na classificação das brincadeiras: conversar; gangorrear edDançar (Femininos, conforme a Fase1); correr, lutar e brincar na oca (Masculinos); e brincar no gira-gira; cavar areia e brincar de pega (Gerais).

As respostas fornecidas pelas crianças (ver Figura 3) demonstraram predominância da classificação Geral (55\% das respostas), sendo $25 \%$ do total das respostas atribuindo brincadeiras às meninas e $20 \%$ aos meninos. Este dado contraria os dados existentes na literatura de maior estereotipia no relato (Silveira, 2003), o que pode indicar o reflexo da proposta pedagógica da escola sobre as verbalizações das crianças ou

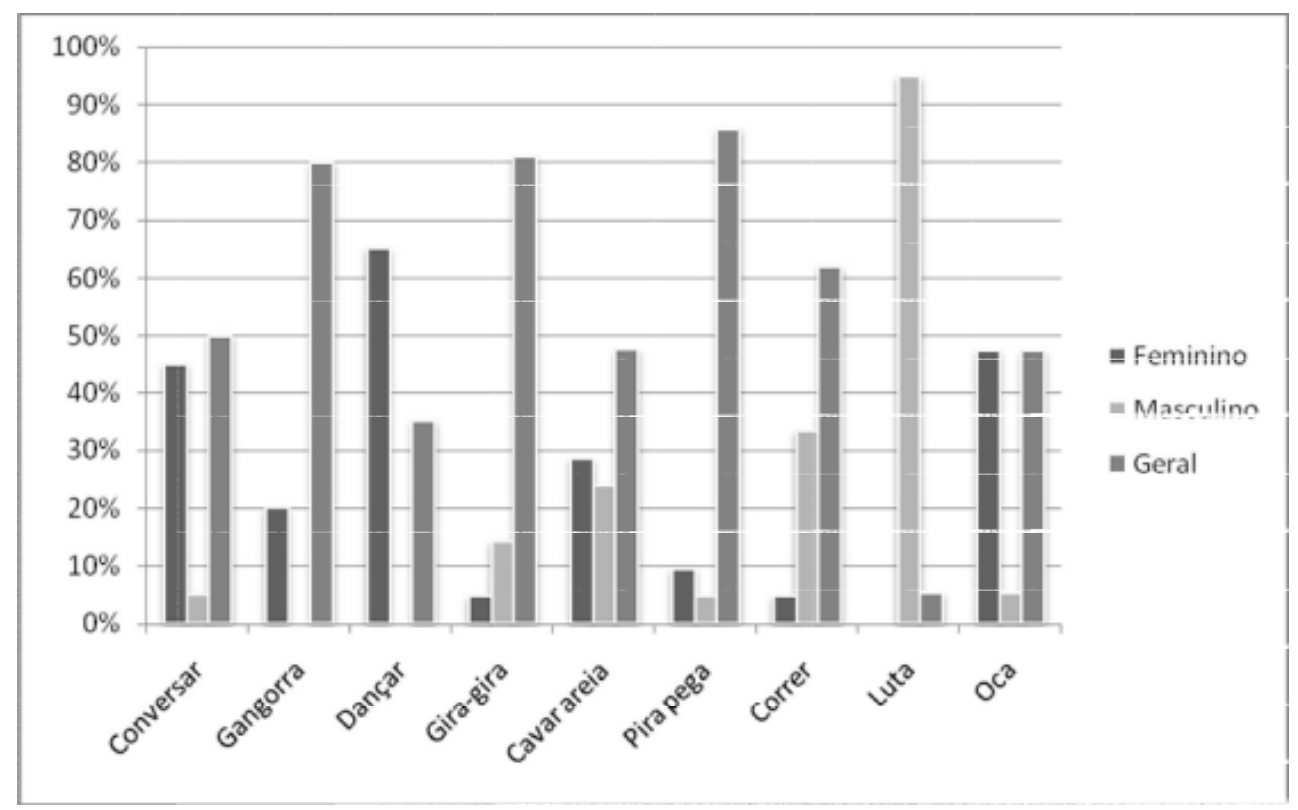

Figura 2. Classificação das categorias pelos participantes

mesmo de mudanças nos costumes e normas sociais sobre os papéis sexuais. O uso da entrevista, como já defendido por Carvalho, Beraldo, Pedrosa e Coelho (2004), reflete mais a concepção das crianças, com maior influência cultural, do que o que realmente é vivido por elas.

As três categorias mais classificadas como "Gerais" foram o "brincar de pega" (86\% das respostas), o "brincar no gira-gira" ( $81 \%)$ e o "gangorrear" $(80 \%)$. Contudo, podese observar a estereotipia sexual também nas respostas da entrevista. A categoria com maior percentual de atribuição ao sexo masculino foi "lutar" (95\%), sendo que "correr", apesar de ter $62 \%$ das respostas como "Geral", foi mais freqüente para o sexo masculino (33\%) que o feminino (5\%). "brincar na oca" havia sido observado como mais freqüente entre os meninos, contudo, nas entrevistas, foi classificado predominantemente como "Geral" ou "Feminino" (47\% em ambas). Como já havia sido percebido na fase de observação e na literatura, a inserção feminina ocorre em um maior número de brincadeiras. Assim, a única categoria que não obteve nenhuma resposta como sendo uma brincadeira feminina foi "lutar", enquanto que "gangorrear" e "dançar" (com 20\% e 65\% de respostas como "Feminino") não obtiveram nenhuma classificação enquanto "Masculinas".

Apesar de ambos os grupos tenderem a classificar as categorias predominantemente enquanto "Gerais", os participantes do sexo masculino classificaram as demais categorias predominantemente como "Masculinas" (63\% das atribuições a apenas um sexo) e as do sexo feminino como "Femininas" (72\% das atribuições a apenas um sexo). Esta diferença na forma de classificar pode indicar que estas classificações eram auto-referenciais, como foi percebido nas respostas quanto ao porquê de suas classificações, por exemplo: "porque eu brinco e fulano também, então é dos dois" ou "porque eu olho pro lado e vejo menino e menina". Estes dados corroboram os achados de Carvalho, Beraldo, Pedrosa e Coelho 
(2004) que encontraram o uso de categorias auto-referenciais principalmente em respostas que atribuíam uma brincadeira a ambos os sexos, enquanto que quando era relatada a estereotipia, as respostas tendiam a refletir valores e normas sociais.

\section{Considerações Finais}

O presente estudo contribuiu com a literatura existente sobre brincadeira ao possibilitar a comparação entre o observado e o falado (na revisão feita por Codazzo, Martins, Macarini, \& Vieira, 2007, as pesquisas tendiam a optar por uma ou outra metodologia). A observação demonstrou-se mais precisa, podendo identificar de que forma os padrões acontecem. Contudo, é um método muito mais trabalhoso e complexo de coleta e análise de dados. As entrevistas, por outro lado, são de simples aplicação, mas demonstraram refletir maior influência de normas culturais sobre o que é falado, bem como de experiências pessoais na formação de regras explicativas. Quanto ao uso de entrevistas com crianças, Carvalho, Beraldo, Pedrosa e Coelho (2004) afirmam que "seus relatos tentam aproximar suas respostas daquelas que se supõem mais aceitas socialmente" (p. 293). Desta forma, o uso de entrevistas deve ser feito para apreender a concepção e a compreensão da criança sobre o brincar, enquanto que "os estudos observacionais fundamentam a possibilidade de descrição e compreensão do funcionamento do espaço natural" (Cordazzo et al., 2008, p.428).

$\mathrm{O}$ presente estudo buscou demonstrar, ainda, que as brincadeiras devem ser observadas de modo a distinguir as diferentes topografias de resposta e as parcerias estabelecidas para a realização de cada uma delas, já que a contabilização final de brincadeiras e de parceiros intra e inter-sexuais (como usualmente se observa na literatura) omite as particularidades das diferenças de gênero nas formas de brincar uma mesma brincadeira. Assim, defende-se a perspectiva de Del Giudice (2009) quanto às diferenças qualitativas entre os sexos e a importância de uma análise mais detalhada, para permitir a identificação de nuances não aparentes em análises mais gerais.

Pode-se perceber, ainda, que a perspectiva interacionista proposta pela Psicologia Evolucionista (que já vem sendo adotada em estudos sobre brincadeiras - ver Burghardt, 2004, e Hansen et al., 2007, como exemplos) possibilita não só o registro das brincadeiras mais freqüentes, mas a reflexão sobre a origem das diferenças de gênero no brincar, focalizando a relevância adaptativa destas predisposições tanto para a sobrevivência do infante quanto para o desenvolvimento apropriado do adulto no Ambiente de Adaptação Evolutiva. Este continuum na forma de se comportar pode ser observado a partir do seguinte paralelo: Lippa (2005) investigou diferenças sexuais na escolha de atividades profissionais em adultos, encontrando resultados similares aos existentes na literatura de brincadeira (Cordazzo Martins, Macarini, \& Vieira, 2007), isto é, homens optando por atividades mais realistas e materiais, enquanto as mulheres preferiam atividades mais abstratas e sociais.

\section{Referências}

Alexander, G., \& Hines, M. (2002). Sex differences in response to children's toys in nonhuman primates (Cercopithecus aethiops sabaeus). Evolution and Human Behavior, 23(6), 467-479.

Beraldo, K. E. (1993). Gênero de brincadeiras de crianças de 5 a 10 anos. Dissertação de Mestrado, Instituto de Psicologia, Universidade de São Paulo, São Paulo.

Biddulph, S. (2006). Criando meninos. São Paulo: Fundamento.

Burghardt, G. M. (2004). The genesis of animal play: testing the limits. Cambridge: MIT Press.

Buss, D. M. (1995). Psychological sex differences: origins through sexual selection. American Psychologist, 50(3), 164-168.

Carvalho, A. M., Beraldo, K. E. A., Pedrosa, M. I., \& Coelho, M. T. (2004). O uso de entrevistas em estudos com crianças. Psicologia em Estudo, 9(2), 291-300.

Conti, L., \& Sperb, T. M. (2001). O brinquedo de pré-escolares: um espaço de ressignificação cultural. Psicologia: Teoria e Pesquisa, 17(1), 59-67.

Cordazzo, S. T. D., Martins, G. D. F., Macarini, S. M., \& Vieira, M. L. (2007). Perspectivas no estudo do brincar: um levantamento bibliográfico. Aletheia, 26, 122-136.

Cordazzo, S. T. D., Westphal, J. P., Tagliari, F. P., Vieira, M. L., \& Oliveira, A. M. F. (2008). Metodologia observacional para o estudo do brincar na escola. Avaliação Psicológica, 7(3), 427-438.

Del Giudice, M. (2009). On the real magnitude of psychological sex differences. Evolutionary Psychology, 7(2), 264-279.

Ellis, B. J. (2004). Timing of pubertal maturation in girls: an integrated life history approach. Psychological Bulletin, 130(6), 920-958.

Hansen, J., Macarini, S. M., Martins, G. D. F., Wanderlind, F. H., \& Vieira, M. L. (2007). O brincar e suas implicações para o desenvolvimento infantil a partir da Psicologia Evolucionista. Revista Brasileira de Crescimento e Desenvolvimento Humano, 17(2), 133-143.

Lippa, R. A. (2005). Subdomains of gender-related occupational interests: do they form a cohesive bipolar M-F dimension? Journal of Personality, 73(3), 693-730.

Luxen, M. F. (2007). Sex differences, Evolutionary Psychology and Biosocial Theory: Biosocial Theory is No Alternative. Theory Psychology, 17(3), 383-394.

Silva, L. I. (2006). Papagaio, pira, peteca e coisas do gênero. Tese de doutorado, Universidade Federal do Pará, Belém.

Silva, L. I. C., Pontes, F. A. R., Silva, S. D. B., Magalhães, C. M. C., \& Bichara, I. D. (2006). Diferenças de gêneros nos grupos de brincadeira na rua: a hipótese de aproximação unilateral. Psicologia: Reflexão \& Crítica, 19(1), 114-121.

Silveira, A. F.(2003). Estereótipos de gênero em brincadeiras infantis. Dissertação de mestrado, Universidade Federal do Pará, Belém.

Taylor, S. E., Klein, L. C., Lewis, B. P., Gruenewald, T. L., Gurung, R. A. R., \& Updegraff, J. A. (2000). Biobehavioral responses to stress in females: tendand-befriend, not fight-or-flight. Psychological Review, 107(3), 411-429.

van de Beek, C., van Goozen, S. H. M., Buitelaar, J. K., \& Cohen-Kettenis, P. T. (2009). Prenatal sex hormones (maternal and amniotic fluid) and gender related play behavior in 13-month-old infants. Archives of Sexual Behavior, $38,6-15$. 
1. Projeto aprovado pelo Comitê de Ética em Pesquisa do Hospital Universitário João de Barros Barreto da Universidade Federal do Pará, Protocolo No 3708/07.

2. Para fotos, diagramas e maiores informações do ambiente de coleta, entrar em contato com a primeira autora.

3. Falar/Conversar; Balançar no banco das professoras; Falar com o observador; Gangorrear; Dar as mãos; Sentar no banco das professoras; Sentar um atrás do outro - "trenzinho"; Correr; Sentar no alto do Gira-Gira; Brincar de luta; Pendurar-se no Gira-Gira; Girar sentando no Gira-Gira; Andar; Sentar; Girar por dentro do Gira-Gira; Ser girado estando sentado; Girar por fora do Gira-Gira; Brincar com o observador; Cavar a areia; Observar grupo; Observar um colega.

4. Pira-bola é uma brincadeira caracterizada por uma criança sendo responsável por procurar os demais participantes, que estão escondidos, enquanto protege uma bola em um local demarcado. Ao encontrar um participante, ambos correm até a bola e se o que procura for o primeiro a chegar, o que estava escondido fica fora da brincadeira. Caso algum dos escondidos conseguir chutar a bola, todos os que estavam fora da brincadeira, são inseridos novamente.

5. Polícia e ladrão é uma brincadeira na qual são formados dois times. O time da polícia deve perseguir os integrantes do time ladrão e, caso os alcance, levá-los a um local definido como cadeia. Os demais membros do time ladrão podem entrar na cadeia e libertar os seus companheiros, caso consigam chegar lá sem serem alcançados pelos membros do time polícia.

6. Jacaré, garrafão, galo, cobra grande e ação são variações de brincadeiras que envolvem corrida, perseguição e luta.

Aline Beckmann de Castro Menezes, mestre em Psicologia Experimental pela Universidade Federal do Pará, é doutoranda em Ecoetologia pela Universidade Federal do Pará e coordenadora do Núcleo de Apoio Psicopedagógico das Faculdades Integradas Ipiranga

Endereço para correspondência: Av. Pedro Miranda, 465/104B, Pedreira, Belém-Pará. CEP - 66085-005. Telefones: (91) 9164-1884/(91) 3264-6994. E-mail: alinebcm@gmail.com

Regina Célia Souza Brito, doutora em Psicologia Experimental pela Universidade de São Paulo, é professora Adjunto na Universidade de São Paulo.

Renata Almeida Figueira é graduanda em Psicologia na Universidade Federal do Pará.

Tatiana Frazão Bentes é graduanda em Psicologia na Universidade Federal do Pará.

Eline Freire Monteiro é graduanda em Psicologia na Universidade Federal do Pará.

Marina Cunha Santos é graduanda em Psicologia na Universidade Federal do Pará. 